\title{
Adversity Quotient Practice and Handwriting Scores in First Grade Students
}

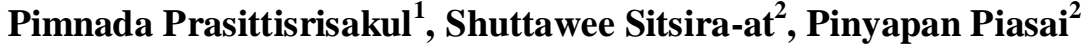 \\ 1. Graduate Student in the Master of Education (Development of Psychology) Program, Srinakharinwirot University \\ 2. Department of Psychology, Faculty of Humanities, Srinakharinwirot University
}

How to cite this paper: Prasittisrisakul, P., Sitsira-at, S. \& Piasai, P. (2017). Adversity Quotient Practice and Handwriting Scores in First Grade Students. The Educational Review, USA, 1(3), 54-60.

http://dx.doi.org/10.26855/er.2017.03.002

Corresponding author: Shuttawee Sitsira-at, Professor, Department of Psychology, Faculty of Humanities, Srinakharinwirot University.

\begin{abstract}
Objective: This study compares the handwriting achievement and Adversity Quotient scores of the first grade students who were studying in the first semester of 2015 academic year of Mekkajorn Chiang Mai School. Materials and methods: 36 first grade students were divided into 2 groups 18 each; a control and an experimental group using a quasi-experimental design. The independent variable was the Adversity Quotient practice, or studying in the classroom without Adversity Quotient practice, and the dependent variables were handwriting achievement and Adversity Quotient. One-way MANOVA was used to analyze the hypothesis of this study. Results: The experimental group had a higher gain score in handwriting achievement and in the Adversity Quotient than the control group, with significances of 0.05 and 0.001 respectively. After finishing the Adversity Quotient practice, the experimental group had a $6.49 \%$ higher score in handwriting achievement and $14.97 \%$ higher score in Adversity Quotient. Conclusion: Adversity Quotient practice helps first grade students of Mekkajorn Chiang Mai School increase handwriting achievement and Adversity Quotient scores.
\end{abstract}

\section{Keywords}

Adversity Quotient, Handwriting, First Grade Students

\section{Introduction}

Students spend a lot of time practice handwriting at school (Amundson \& Weil, 2001). Handwriting is important and is related to learning ability and self-esteem (Feder \& Majnemer, 2007). Generally, students quickly develop the quality of their handwriting at Grade 1 or during the first 6 to 7 years of age (Overvelde \& Hulstijn, 2011). Students learn handwriting according to the core curriculum of basic education of the year 2008. At the end of Grade 1, they are able to neatly handwrite, have perfect orthography and know the correct position of vowels, tones, silent symbols and all other symbols. They also know where to put spaces between sentences and are responsible for their handwriting (The Ministry of Education Thailand, 2008).

Handwriting is an important activity. Neat and correct handwriting helps foster good habit and concentration (Bureau of Academic Affairs and Educational Standards Thailand, 2012) Incorrect practice of handwriting may result in certain problems such as leaning letters, using too much pressure, writing too slowly, writing unclear alphabets, misplacing of vowels and punctuation and lacking spaces (Sukkasem, 1968; Somprayoun, 2010). We have interviewed and observed the first grade students who were studying in the first semester of 2015 academic year of Mekkajorn Chiang Mai School. The results revealed that 27.02 per cent of the students had a problem with handwriting. The major problems are unevenly written letters, slow writing, inconsistent spaces, incorrect postures and leaning letters. 
As a result, we aim to help these students solve their problem and help them succeed in handwriting. After having done literature review, we found that students need development of certain skills since writing is a complicated skill which requires many components. Amundson (2001) and Smith (2005) suggests that three components for handwriting legibility and speed are 1) sensory-motor components such as visual, muscle tone and strength, fine motor coordination and visual-motor integration 2) cognitive components such as attention, recalling letter formation and generalization and 3) psychosocial components such as

values and interest, self-regulation, self-concept and coping skills. This last component is important in raising the handwriting score. The reason is that self-esteem, confidence and motivation are key factors for success in handwriting (Pajares, 2003; Pajares \& Valiante, 2006; Graham, S., Virginia, B. \& Fan, W. H., 2007)

Moreover, another psychosocial component that may encourage students to solve handwriting problem is Adversity Quotient: AQ, which is a score that measures the ability of a person to deal with adversities in his or her life (Kumbannaruk, 2008). The term was coined by Stoltz (1997). This ability is one of the probable indicators of a person's success in addition to IQ and EQ. It consists of 4 components: 1) Control: the person perceives themselves as being in control of their obstacles and of their reaction to the obstacles 2) Origin and Ownership: the person knows the origin of the obstacle and realizes that they are responsible for the obstacle 3) Reach: the person understands that obstacles are solvable4) Endurance: the person perseveres through toughness of the obstacle until they achieve. A person with a high score of AQ is more likely to achieve than those with a low score of AQ. Research shows that AQ scores also have a correlation with learning outcomes (D'Souza, 2006) and mathematics test scores (Boontawee, 2012).

However, AQ can be developed. Stoltz (1997) proposed a technique to develop the ability to overcome obstacles called "LEAD sequence". It consists of 4 steps: listen to your adversity response (L), explore all origins and your ownership of the result (E), analyze the evidence (A) and do something (D).

Therefore, we aim to develop handwriting skills by enhancing the adversity ability. The research question is whether the students will perform better in handwriting after having been trained to overcome obstacles. We developed an AQ training program based on Stoltz's LEAD sequence as well as including the psychosocial components proposed by Amundson. This AQ training will be useful in enhancing the students' patience and their handwriting scores which will result in better writing in general. It can also develop self-control, the ability to analyze the problems, to find the solutions and to self-help. These are the roles of psychologists to develop students' skills to help them achieve in school.

\section{Materials and Methods}

The subjects were divided into 2 groups using a non-equivalent control pretest post-test design (Donald, \& Julian, 1996) with 18 subjects in each group. It is a quasi-experimental design. The control group has higher scores in handwriting and the experimental group has lower scores in handwriting. The subjects were tested before and after the experiment. The experimental group was trained with the adversity quotient practice while the control group was not.

\subsection{Subjects}

Subjects were 36 out of 49 first grade students in the first semester of academic year 2015 of Mekkajorn Chiang Mai, Amphoe Mae Tang, Chiang Mai province. Twelve students did not meet the exclusion criteria as detailed below.

1. Three of them have autism spectrum disorder, attention-deficit-hyperactive disorder and learning disabilities.

2. Three of them are hill-tribes who do not use Thai as their first language.

3. Five of them have communication and developmental problems.

4. Two of them have behavioral problems or are not ready to participate in the research.

The subjects were divided into two groups according to their scores in handwriting. The first 18 students with the highest 
scores were in the control group. The other 18 students who got lower scores were in the experimental group.

\subsection{Tools and Evaluation}

\section{Adversity Quotient Test}

This test was created under two frameworks: Adversity Response Profile by Stoltz (1997) and the Semantic differential scale or Bipolar scale created by Plakatthong (2008). The students rank their answer on the scale from 1 to 6 . If the students choose a higher number, that means they have higher Adversity Quotient than those who choose lower number. The questions were divided into 8 questions for general adversity general and 4 questions for adversity in handwriting. The questions cover the four components of Adversity Quotient for the total of 22 questions. The four components are control, origin and ownership, reach and endurance. The certainty rate of the test is .47 .

Handwriting Test

The handwriting test was created based on the evaluation of the core curriculum of basic education of the year 2008, the criteria of handwriting evaluation of Elementary Education in Nakhon Ratcha Sima District 3 and the criteria of Samart Meesee (Boontawee, 2012). The test rubric consists of 6 aspects: correctness (15 points), neatness (15 points), alphabet quality (30 points), spacing (20 points), positioning (10 points) and cleanness (10 points) with the total of 100 points. We evaluate the quality of the tools by inter-rater reliability. The correlation is .73.

Adversity Quotient Practice

This program is developed by compiling topics in research on adversity quotient and handwriting. The program was made to correspond to the adversity quotient glossary. It consists of 7 practices for 30 minutes each. The detail of each practice is as follows.

Practice 1: Learn how to problem-solve with a story

Practice 2: Realize the problems that occur in the game and realize one's ability to solve the problem using LEAD sequence via game

Practice 3: Find the origin of problems from role play and evaluate one's own handwriting and one's ownership of the problem Practice 4: Know the boundary of the problem, distinguish between facts and beliefs via game and try to find the solution on one's own

Practice 5: Practice endurance via game and in handwriting

Practice 6: Concentrate and exercise self-control to do the assigned task

Practice 7: Review all exercises and practice handwriting

\subsection{Data Analysis}

Descriptive statistics is conducted to analyze and find an average and standard deviation of the achievement in handwriting and adversity quotient.

One-way MANOVA is conducted to study the effect of the adversity quotient practice on handwriting.

\section{Results}

The results are divided into two parts.

Part 1: Basic statistics of dependent variables.

We divided students into a control and an experimental group according to their handwriting achievement scores. Those who 
had high scores were in the control group and those with low scores were in the experimental group. To answer the research question, we find the difference between scores in the pre-test and post-test or gain score. The results are presented below.

1. After the experiment, the experimental group has a higher average score in handwriting achievement than that of the control group by 6.49 per cent (for the total of 100 points). The experimental group also has a higher average score of Adversity Quotient by 14.97 per cent (for the total of 72 points) as shown in Table 1.

Table 1. Mean (M) Standard Deviation (SD) of Gain score of Adversity Quotient (AQ) and Handwriting (HW) for the experimental group and the control group.

\begin{tabular}{ccccc}
\hline \multirow{2}{*}{ Variable } & \multicolumn{2}{c}{ Experimental Group $(\mathrm{n}=18)$} & \multicolumn{2}{c}{ Control Group $(\mathrm{n}=18)$} \\
\cline { 2 - 5 } & $\mathrm{M}$ & $\mathrm{SD}$ & $\mathrm{M}$ & $\mathrm{SD}$ \\
\hline $\mathrm{HW}$ & 6.49 & 4.45 & 3.10 & 4.39 \\
$\mathrm{AQ}$ & 10.78 & 11.95 & -2.33 & 9.69 \\
\hline
\end{tabular}

*NB: HW represents the handwriting score

AQ represents the Adversity Quotient score

After the experiment, 17 students of the experimental group received a higher score and only 1 student received a lower score for handwriting. On the other hand, 15 students of the control group received a higher score and 3 of them received a lower score for handwriting. As for the Adversity Quotient, 15 students of the experimental received a higher score, 1 received the same score and 2 received a lower score. In contrast, 7 students of the control group received a higher score, 2 received the same score and 9 received a lower score.

Part 2: Data analysis to test the hypothesis.

One-way MANOVA results of AQ scores and handwriting scores in the control group and experimental group

We examined basic assumptions that include correlation, normality, homogeneity of covariance matrices and equality of error variances. We found that all the basic assumptions were met. We compared the differences between the AQ scores and handwriting scores of both groups in Table 2 .

Table 2. One-way MANOVA results for AQ and Handwriting (HW) scores.

\begin{tabular}{cccc}
\hline Statistics & \multicolumn{2}{c}{ Multivariate } & Univariate \\
\cline { 2 - 4 } & & HW & AQ \\
MSE & $7.18^{* *}$ & $5.07^{*}$ & $13.06^{* * *}$ \\
MSE & & 99.17 & 1547.11 \\
\hline
\end{tabular}

$* \mathrm{p}<.05, * * \mathrm{p}<.01, * * * \mathrm{p}<.001$

NB: F uses the Wilks' Lambda criteria

a. Multivariate $\mathrm{df}=2,33$,

b. Univariatedf $=1,34$

From Table 2, the results of Wilk's Lambda show that the difference between the AQ scores of the experimental group and those of the control group are statistically significant at 0.05 .

The one-way repeated MANOVA of the AQ scores and handwriting achievement scores of the experimental group before and after the experiment before and after the experiment

Since we measure the students before and after the experiment with two correlated dependent variables, we had to run a one-way repeated measure MANOVA and test the basic assumptions before analyzing the data. It was found that the data comply with the basic assumption. We then calculated the difference between the scores before and after the experiment. We found that the handwriting and AQ scores before and after the experiment are statistically significant at .001 as shown in Table 3. 
Table 3. Results of one-way repeated MANOVA of AQ and handwriting achievement scores before and after the experiment in the experimental group.

\begin{tabular}{|c|c|c|c|}
\hline \multirow{2}{*}{ Statistics } & \multirow[t]{2}{*}{ Multivariate } & \multicolumn{2}{|c|}{ Univariate } \\
\hline & & HW & $\mathrm{AQ}$ \\
\hline F & $21.78 * * *$ & $14.63^{* *}$ & $38.29 * *$ \\
\hline MSE & & 1045.44 & 380.250 \\
\hline
\end{tabular}

\section{Discussion}

The results show that the experimental group who underwent the Adversity Quotient practice gained higher scores for handwriting achievement than the control group who did not undergo the practice. The experiment group also improved their handwriting scores after the experiment. The results reveal that Adversity Quotient practice has an impact on handwriting achievement scores as predicted. It may be because handwriting requires psychosocial readines (Boonsawat, 1989) in addition to muscle control and intelligence. Students need self-regulation, self-concept and coping skills. This finding is in accordance with Stoltz's proposal that Adversity Quotient is a factor of success in addition to Intelligence Quotient and Emotional Quotient. We noticed that low scores of handwriting achievement result from many factors, for example unclear letters due to lack of a circle (most Thai alphabets contain one or two circles), disproportionate letters, misplace of the letters and symbols, lack of spacing, uneven letters and lack of neatness. Therefore, in order to improve handwriting, students must realize what their mistakes are and know how to correct those mistakes. The Adversity Quotient practice helped students realize their problems in handwriting, evaluate their handwriting and learn how to solve those problems. The experimental group learned to perceive their own problems and took ownership of the problems by finding ways to solve them. They also persevere and control themselves to achieve neat handwriting. Previous research also found that Adversity Quotient has an impact on learning (D'Souza, 2006) and achievement in mathematics (Boontawee, 2012).

The results also reveal that the experimental group also gained higher scores in Adversity Quotient than the control group. The Adversity Quotient practice was developed based on the LEAD Sequence technique proposed by Stoltz (1997). The students were trained to 1) listen to and respond to the problem immediately (L) 2) practice the steps to solve the problem, find boundary and take ownership of the result (E) 3) distinguish between facts and thoughts to stop the Domino Effect of the problem as well as find feasible solutions (A) and 4) take action (D) under the supervision of the researchers. The experimental group improved their AQ score which proves Stoltz's idea that AQ can be developed. The principles can be applied to individuals of any genders and ages. Our results confirm previous research's findings on an AQ practice program in many age groups such as working group (Vivitsiri, 2007), university group (Nacharoen, 2013; Sitsira-at, 2010), high school group (Chotikapanit, 2006) and elementary group (Pargudtong, 2008). These works yielded the same findings that the experimental group gained higher Adversity Quotient scores after having undergone the AQ practice program.

When we compare the handwriting achievement scores and Adversity Quotient scores of the experimental group before and after the experiment, we find that their handwriting and Adversity Quotient scores increase after the experiment. This means that the Adversity Quotient practice helped improve the students' handwriting and Adversity Quotient. The experimental students were trained to confront the obstacles and participated in activities that help develop Adversity Quotient in handwriting for a total of 7 times. In those practices, they underwent the following steps. First, the students listened to the story 'A thirsty crow and a huge water jug' so that they see an example of how to problem-solve through the story of a crow. The crow represents a person with a high Adversity Quotient and succeeds in problem-solving. After that, the researchers showed the students the chart of CORE components of Adversity Quotient and explained how it related to the story. Next, the students play a game 
called 'Searching for a star' in order to let them solve problems on their own via role play. The researchers asked questions to stimulate the students to think and try to solve the problem according to Stoltz's LEAD Sequence. Then the researchers concluded the steps to develop Adversity Quotient. The third step is the activity called 'My handwriting'. The students realized the problems about their handwriting. Then they played a matching-the-pictures game called 'Every problem has a cause' so that they can think of the origin of a problem. The researchers then talked about a case study of a student who has a trouble in handwriting. The students then analyzed their own handwriting. The fourth step is where the students were train to stop the Domino Effect of the problem via role plays and case studies. In the fifth step, the students persevered through handwriting when sitting straight. In the sixth step, the students were trained to concentrate with games and to write when surrounded by stimulations and in the final step, the researchers reviewed all the tasks that the students had gone through.

\section{Conclusion}

The first grade students of Mekkajorn Chiang Mai School who underwent Adversity Quotient practice gained higher scores for handwriting achievement and Adversity Quotient than those who did not undergo the practice. The gain scores are statistically significant at .05 and .001 respectively. After having undergone the practice, the experimental group gained handwriting achievement scores by 6.49\% and gained Adversity Quotient scores by $14.97 \%$.

\section{Acknowledgements}

We would like to thank the Graduate School of Srinakharinwirot University for the funding of this project. We are also thankful to Mekkhajorn Chiang Mai School for their cooperation in conducting the research.

\section{References}

Amundson, S. J. \& Weil, M. (2001). Prewriting and Handwriting Skills. Journal of Applied Psychology, 32, $221-233$.

Bureau of Academic Affairs and Educational Standards Thailand. (2012). A Handbook of Thai Language for Grade 1 No.1. Bangkok: Office of the Basic Education Commission. Ministry of Education.

Boonsawat, P. (1989). When A Child Learn To Write. Bangkok: Plan Publishing.

Boontawee, P. (2012). Development of a Causal Model of Intelligence Quotient, Emotional Quotient, Moral Quotient, Adversity Quotient and Analytical Thinking Ability on Mathematics Learning Achievement of Prathomsueksa 6 Students under the Office of Nongkhai Service Area Zone 1. Journal of Educational Measurement Mahasarakham University, 18, 119-134.

Chotikapanit, N. (2006). A Study and Development of Adversity Quotient in Studying of Adolescent Students. M.S. Thesis, Bangkok: Srinakharinwirot University.

D'Souza, R. (2006). A Study of Adversity Quotient of Secondary School Students in Relation to their School Performance and the School Climate. Accessed 31 August, 2014. http://www.peaklearning.com/documents/PEAK_GRI_dsouza.pdf.

Donald, T. C. \& Julian, C. S. (1996). Experimental and Quasi-experimental Designs for Research. Chicago: Rand Mcnally College Publishing Company.

Feder, K. P. \& Majnemer, A. (2007). Handwriting Development, Competency, and Intervention. Developmental Medicine and Child Neurology. 49(4), 312-317.

Graham, S., Virginia, B. \& Fan, W. H. (2007). The Structural Relationship between Writing Attitude and Writing Achievement in First and Third Grade Students. Contemporary Educational Psychology, 32(3), 516-536.

Kumbannaruk, T., trans. (2008). AQ: The Power of Success. 3rd edition. Bangkok: Biskiss

Nacharoen, J. (2013). The Development of Training Model on Adversity Quotient for Early Childhood Student-Teachers. M.S. Thesis, Bangkok: Srinakharinwirot University.

Overvelde, A. \& Hulstijn, W. (2011). Handwriting Development in Grade 2 and Grade 3 Primary School Children with Normal, at Risk, or Dysgraphic Characteristics. Research in Developmental Disabilities, 32(2), 540-548.

Pajares, F. (2003). Self-efficacy Beliefs, Motivation, and Achievement in Writing: A Review of the Literature. Reading and Writing Quarterly, 19(2), 139-158.

Pajares, F. \& Valiante, G. (2006). Self-efficacy Beliefs and Motivation in Writing Development, edited by MacArthur, C., Graham, S. \& 
Fitzgerald, J. (Eds.), Handbook of Writing Research. (pp. 158-170). New York: Guilford Press.

Pargudtong, P. (2008). A Development of the Learning Model for Enhancing Adversity Quotient of the Second Level Students. M.S. Thesis, Bangkok: Srinakharinwirot University.

Sitsira-at, S. (2010). Antecedent and Consequence Factors of Self-Directed Learning of Undergraduate Students at Srinakharinwirot University. Journal of Behavioral Science Research, 16 (2), 66-82.

Smith, J. (2005). Occupational Therapy for Children. (4th ed). Philadelphia: Elsevier Mosby.

Somprayoun, W. (2010). Teaching for Thai Language. Bangkok : Flower Grass Academic.

Stoltz, P. G. (1997). Adversity Quotient: Turning Obstacles into Opportunities. United State of America: John Wiley \& Sons.

Sukkasem, A. (1968). Teaching Children to Start Learning. Public Education. 151-159.

The Ministry of Education Thailand. (2008). Basic Education Core Curriculum of Thailand. Accessed 10 August 2015, http://www.curriculum51.net/viewpage.php?t_id=95.

Vivitsiri, W. (2007). A Construction of Training Program for Development on Adversity Quotient at Work for Registered Nurse. M.S. Thesis, Bangkok: Srinakharinwirot University. 